\title{
Development and Evaluation of a SYBR Green-Based, Real-time Polymerase Chain Reaction for Rapid and Specific Detection of Human Coxsackievirus B5
}

\author{
Kyu Bong Cho ${ }^{\dagger, *}$ \\ Department of Biomedical Laboratory Science, Shinhan University, Uijeongbu 11644, Korea
}

\begin{abstract}
Human Coxsackievirus B5 (HuCoxV-B5) infection has been associated with various diseases such as myocarditis, aseptic meningitis, hand-foot-and mouth-disease, and insulin-dependent diabetes. HuCoxV-B5 is a virus transmitted through the fecal-oral route and is detected in clinics, aquatic environments, food, shellfish, etc. and is one of the more important viruses in public health because of its incidence rate reported worldwide. In this study, a combination of SYBR Green-based real-time PCR primers for molecular diagnosis including monitoring of HuCoxV-B5 was selected and the optimal reaction conditions were established. Compared with the previously reported TaqMan probe-based real-time PCR method, assessments including a sample applicability test were performed. Results showed that the real-time PCR method developed in this study was suitable for a molecular diagnostic technique for detecting HuCoxV-B5. This study is expected to contribute to efforts in responding to safety accidents in public health because the proposed method facilitates rapid diagnosis of clinical patients. It can also be used as a specific monitoring tool of HuCoxV-B5 in non-clinical areas such as aquatic environments among others.
\end{abstract}

Key Words: Human Coxsackievirus B5, HuCoxV-B5, Real-time PCR, SYBR green

\section{서 론}

Human Coxsackievirus (HuCoxV)는 Poliovirus, Parechovirus 등과 함께 주요 Enterovirus 그룹에 포함되며, 한국, 미국, 중국, 이탈리아 등 선진국을 포함하여 전 세계적 으로 빈번하게 보고되고 있어 공중 보건학적으로 중요 한 바이러스 중 하나로 꼽힌다(Wagenknecht et al., 1991; Chen et al., 2012; Hyeon et al., 2013; Fontana et al., 2019). $\mathrm{HuCoxV}$ 에 포함된 $\mathrm{A}$ 와 $\mathrm{B}$ 중 $\mathrm{B}$ 그룹은 감염 시 일반적 으로 무증상이지만, 수막염, 뇌염, 심근염, 경련성 마비, 발진, 호흡기 질환 등의 사례가 보고되었다(Zhang et al., 1993; Triantafyllopoulou et al., 2004; Papa et al., 2006; Gullberg et al., 2010; Hu et al., 2012). 이 중에서도 B5형(HuCoxV-B5) 은 사람에게 가장 우세하게 나타나는 혈청형으로 바이러 스성 심근염의 일반적 원인, 산발적으로 발병하는 확장성 심근 병증의 약 $25 \%$ 이상의 원인, 무균성 수막염, 신경적 수족구병, 인슐린 의존성 당뇨병 등 다양한 질병과의 연 관성이 보고되고 있다(Papa et al., 2006; Gullberg et al., 2010; $\mathrm{Hu}$ et al., 2012). HuCoxV-B5 등 Enterovirus 그룹에 포함되 는 바이러스들은 분변-구강 경로로 전염 또는 오염되는 대표적인 장 관계 바이러스이며, 임상 외 수계 환경, 식품, 패류 등에서도 검출되므로 다양한 매질에서의 모니터링은 공중 보건학적으로 중요하다(Cho, 2018; Lee and Cho, 2019). 그러나 Enterovirus 그룹에 포함되는 바이러스들은 약 70 종류 이상의 혈청형으로 구성된다(Oberste et al., 1999). 이

Received: October 15, 2020 / Revised: November 27, 2020 / Accepted: November 30, 2020

* Professor.

${ }^{\dagger}$ Corresponding author: Kyu Bong Cho. Department of Biomedical Laboratory Science, Shinhan University, Uijeongbu 11644, Korea. Tel: +82-31-870-3712, Fax:+82-31-870-3719, e-mail: kbcho@shinhan.ac.kr (C) The Korean Society for Biomedical Laboratory Sciences. All rights reserved.

(C) This is an Open Access article distributed under the terms of the Creative Commons Attribution Non-Commercial License (http://creativecommons.org/licenses/by-nc/3.0/) which permits unrestricted non-commercial use, distribution, and reproduction in any medium, provided the original work is properly cited. 


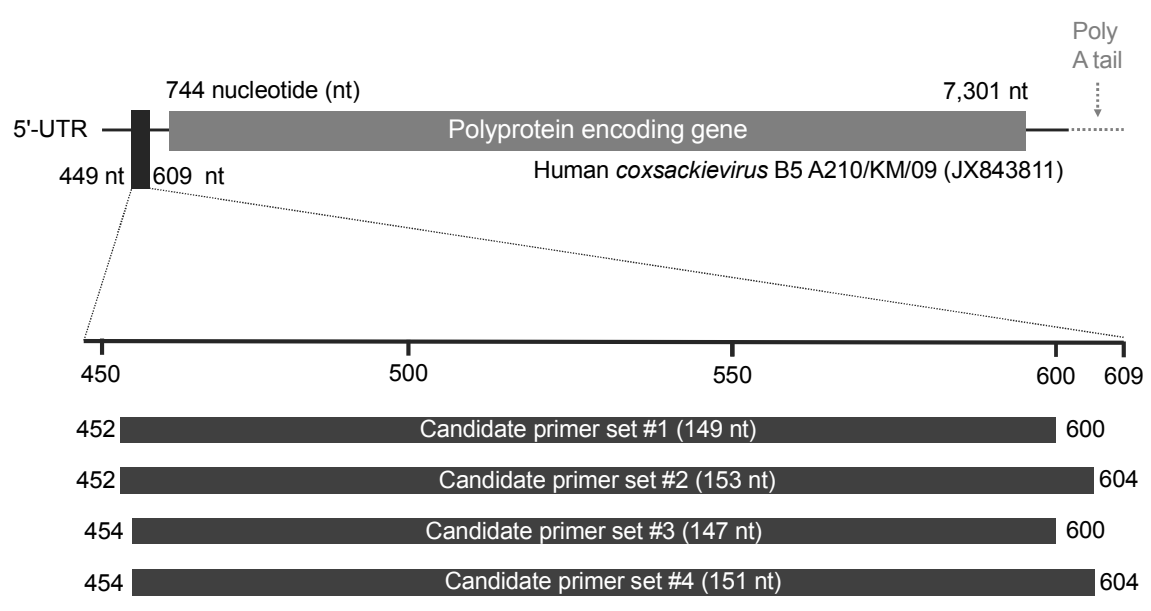

Fig. 1. SYBR Green-based, real-time PCR primer map for the detection of Human Coxsackievirus B5 (HuCoxVB5).
들은 대부분 사람과 관련된 병원성 바이러스이며, 보고된 Enterovirus 혈청형들의 짧은 유전자 단편들의 복잡한 유 연관계 등으로 특정 한 종류의 검출보다는 pan-enterovirus 등 Enterovirus 그룹을 전체적으로 모니터링 할 수 있는 항원-항체 및 분자적 기술이 연구되어 왔다(Lee and Jeong, 2004; Choi et al., 2013). 그러나 각 혈청형 별 다르게 나타 나는 질병, 유행, 거동 특성 등으로 개별적 모니터링의 필 요성이 제기되었으며, 71형 및 68형 Enterovirus 등을 중심 으로 개별적 진단 기법들이 보고되었다(Tan et al., 2008). HuCoxV-B5 검출을 위해 항원-항체 기반의 enzyme-linked immunosorbent assay (ELISA)법이 사용되었으나(Kopecka et al., 1995), ELISA 기법은 위 양성, 검출 민감도, 객관적 판독 등의 문제점으로 인하여 최근에는 분자진단 기법들 이 보고되고 있다(Lee et al., 2013). Jaianand et al. (2011), Zhao et al. (2013)에 의해 HuCoxV-B5 검출용 등온증폭법 [loop-mediated isothermal amplification (LAMP)]이 보고되었 으나, LAMP는 알 수 없는 비 특이적 증폭으로 인한 위 양성 반응, 상대적으로 고가의 비용, 좁은 범위의 사용자 등의 문제점이 보고된 바 있다(Hardinge and Murray, 2019; Schneider et al., 2019). Rezig et al. (2004) 등에 의해 일반 $\mathrm{PCR}$ 방법이 보고되었으나, 미량 오염 및 다수의 $\mathrm{PCR}$ 저 해 물질이 포함된 환경 시료에서 요구되는 높은 특이성과 우수한 검출 민감도 문제를 해결하기 위해서는 PCR 증 폭 후 증폭 산물을 주형으로 다시 한 번 증폭하는 nested $\mathrm{PCR}$ 의 활용, $\mathrm{PCR}$ 저해 물질을 감소시키는 reagent의 사용 등으로 해결해야 하며, 상대적으로 복잡한 검사 과정, 전 기영동 등으로 약 10 시간 이상이 소요되는 한계점이 있 었다(Lee et al., 2015; Lee et al., 2017). 한편 real-time PCR은 단일 과정으로 상대적으로 간편하고, 2 시간 이내의 빠른
검출이 가능하며, nested PCR과 동등 이상 수준의 검출 민 감도를 가진 기법으로 최근 임상과 비 임상에서 주요 분 자진단 기법으로 활용되고 있다(Chen et al., 2017; Yoo et al., 2017; Corman et al., 2020). Mohamed et al. (2004)와 Kang et al. (2013)에 의해 VP1 일부 유전자 단편을 증폭하는 realtime PCR 방법이 보고되었으나, 특이성, 검출 민감도, 시 료 적용성 평가 등의 연구는 미흡하다.

따라서 이번 연구에서는 HuCoxV-B5를 신속 및 특이적 으로 검출할 수 있는 real-time PCR 방법을 개발하였으며, 환경 시료 등에서의 활용성을 평가하였다.

\section{재료 및 방법}

\section{프라이머 설계 및 바이러스 핵산 수집}

HuCoxV-B5 특이적 검출을 위한 프라이머 조합은 Mohamed et al. (2004)를 구성 예정인 PCR 조성물과 조건 에 맞추어 변형 및 재설계 하였으며 (Table 1 and Fig. 1), Oligo Calculator version 3.27로 잠재적 hairpin 형성, self annealing 등을 검정하였다. 한편, HuCoxV-B5 5'-UTR 부 분을 대상으로 핵산 단편을 증폭하는 검사법을 고안하기 위하여 National Center for Biotechnology Information (NCBI) accession number JX843811 기준 449-609 nucleotide (nt) (161 nt)를 마크로젠(Seoul, Korea)에 의뢰하여 단일 가닥으 로 합성 및 유관 기관에서 $\mathrm{HuCoxV}-\mathrm{B} 5 \mathrm{cDNA}$ 를 수집하였 다. 또한 비 특이적 반응에 사용할 참고 바이러스 15종 [Adenovirus 41 (AdV-41), Aichivirus A (AiV-A), Aichivirus B (AiV-B), Aichivirus C (AiV-C), Astrovirus (AstV), Enterovirus 71 (EV-71), Enterovirus 68 (EV-68), Hepatitisvirus A (HAV), Hepatitisvirus E (HEV), Norovirus GI (NoV-GI), Norovirus GII 
Table 1. Specific PCR primer sets for the detection of HuCoxV-B5

\begin{tabular}{|c|c|c|c|c|c|c|c|}
\hline \multirow{2}{*}{ Set \# } & \multirow{2}{*}{ Primer name } & \multirow{2}{*}{ Sequence (5'-3') } & \multirow{2}{*}{$\begin{array}{l}\text { Mer } \\
\text { (nt) }\end{array}$} & \multicolumn{2}{|c|}{ Location } & \multirow{2}{*}{$\begin{array}{l}\text { Product } \\
\text { size (nt) }\end{array}$} & \multirow{2}{*}{ Reference } \\
\hline & & & & Start & Stop & & \\
\hline \multirow{2}{*}{1} & CoxV-B5_F452 & CCGGCCCCTGAATGCGGCTA & 20 & 452 & 471 & \multirow{2}{*}{149} & \multirow{2}{*}{-} \\
\hline & CoxV-B5_R600 & TGTCACCATAAGCAGCCAGTGTAGG & 25 & 576 & 600 & & \\
\hline \multirow{2}{*}{2} & CoxV-B5_F452 & CCGGCCCCTGAATGCGGCTA & 20 & 452 & 471 & \multirow{2}{*}{153} & \multirow{2}{*}{-} \\
\hline & CoxV-B5_R604 & CAATTGTCACCATAAGCAGCCAG & 23 & 582 & 604 & & \\
\hline \multirow{2}{*}{3} & CoxV-B5_F454 & GGCCCCTGAATGCGGCTA & 18 & 454 & 471 & \multirow{2}{*}{147} & \multirow{2}{*}{-} \\
\hline & CoxV-B5_R600 & TGTCACCATAAGCAGCCAGTGTAGG & 25 & 576 & 600 & & \\
\hline \multirow{2}{*}{4} & CoxV-B5_F454 & GGCCCCTGAATGCGGCTA & 18 & 454 & 471 & \multirow{2}{*}{151} & \multirow{2}{*}{-} \\
\hline & CoxV-B5_R604 & CAATTGTCACCATAAGCAGCCAG & 23 & 582 & 604 & & \\
\hline \multirow{3}{*}{ Ref. \#1 } & NMF1 & GCCCCTGAATGCGGC & 15 & 455 & 469 & \multirow{3}{*}{149} & \multirow{3}{*}{$\begin{array}{l}\text { Mohamed } \\
\text { et al., } 2004\end{array}$} \\
\hline & NMR1 & AATTGTCACCATAAGCAGC & 19 & 585 & 603 & & \\
\hline & TaqMan $^{\circledR}$ probe & $\begin{array}{l}\text { HEX-CGGAACCGACTACTTTGGGTGTCCGT- } \\
\text { BHQ1 }\end{array}$ & 26 & 537 & 562 & & \\
\hline \multirow{3}{*}{ Ref. \#2 } & CVB F & AAACCCAAACATGTGAAGGCGTGG & 24 & 3,166 & 3,189 & \multirow{3}{*}{118} & \multirow{3}{*}{$\begin{array}{l}\text { Kang et al., } \\
2013\end{array}$} \\
\hline & CVB R & TGGTAATGTTTGAGCGCGTTGTGG & 24 & 3,260 & 3,283 & & \\
\hline & CVB P & $\begin{array}{l}\text { HEX-ACCGCCGAGGCTATGTCAATATGAGA- } \\
\text { BHQ1 }\end{array}$ & 26 & 3,198 & 3,223 & & \\
\hline
\end{tabular}

(NoV-GII), Orthoreovirus segment S (OrV-S), Parachovirus A (PeV-A), Poliovirus type 3 (PV-type3) 및 Sapovirus (SaV)]의 핵산 염기서열 일부를 단일 가닥의 plasmid로 합성하였다.

\section{프라이머 선발}

$\mathrm{HuCoxV-B5}$ 에 특이적 반응이 추정되는 4개의 후보 프 라이머 조합의 특이적 반응 및 검출 민감도를 분석하였 다. HuCoxV-B5 plasmid $1 \mathrm{ng} / \mu \mathrm{L}$ 기준으로 $10^{-6}(1 \mathrm{fg} / \mu \mathrm{L})$ 까 지 10 배 단계 희석하였으며, cDNA는 $1,000,500,250,100$, 50, 10 copies 및 1 copy로 희석하였다. HuCoxV-B5 plasmid 와 $\mathrm{cDNA}$ 를 희석액을 주형으로 SYBR Green 기반의 realtime PCR을 수행하였으며, 조성은 $\mathrm{iTaq}^{\mathrm{TM}}$ Universal SYBR $^{\circledR}$ Green Supermix (Biorad, USA) $10 \mu \mathrm{L}$, 정 방향 및 역 방향 프라이머 $2 \mu \mathrm{L}(25 \mathrm{pmol} 1 \mu \mathrm{L}$, each), 주형 핵산 $1 \mu \mathrm{L}$ 및 nucleic acid free water $7 \mu \mathrm{L}$ 로 총 $20 \mu \mathrm{L}$ 로 하였다. Real-time $\mathrm{PCR}$ 조건은 $95^{\circ} \mathrm{C}$ 에서 5 분간 1 회 초기 변성 후, $95^{\circ} \mathrm{C}$ 에서 15 초, $61{ }^{\circ} \mathrm{C}$ 에서 60 초를 35 회 반복하였다. 또한 특이적 반 응 및 검출 민감도에서 우수한 결과를 보인 프라이머 조 합을 대상으로 비 특이적 반응을 수행하였다. 주형 핵산 으로 positive control [HuCoxV plasmid $(100 \mathrm{pg} / \mu \mathrm{L})]$, negative control [nucleic acid free water], 참고 바이러스 15종 핵산 (AdV-41, AiV-A, AiV-B, AiV-C, AstV, EV-71, EV-68, HAV,
HEV, NoV-GI, NoV-GII, OrV-S, PeV-A, PV-type 3 및 SaV)을 주형으로 반응하였다. 반응 조성 및 조건은 특이적 반응 과 동일하게 하였다.

\section{선발 프라이머의 평가}

선발한 real-time PCR 프라이머의 평가를 위하여 기존 보고된 $\mathrm{HuCoxV-B5}$ 검출용 real-time PCR 방법과 검출 민 감도 및 특이성을 비교하였다(Table 1). Real-time PCR 조 성은 $\mathrm{cDNA}$ 를 주형으로 사용 및 개발 프라이머 조건과 동일하게 하였으며, 조건은 각각의 보고된 방법과 동일하 게 하였다(Mohamed et al., 2004; Kang et al., 2013). 또한 시 료 적용성 시험을 위하여 환경부 국립환경과학원 20072016 관련 모니터링 자료(Lee et al., 2018)를 바탕으로 오 염이 예상되는 지역 중 10 개 지점의 지하수 시료를 무작 위 채취하였으며, 실험실로 이동 후 탈리 및 농축을 수행 하였다. 농축 시료에서 QIAamp ${ }^{\circledR}$ Viral RNA Mini (Qiagen, Germany)로 total RNA를 추출 후, ReverTra Ace- $\alpha-{ }^{\mathrm{TM}}$ (Toyobo, Japan)을 사용하여 cDNA로 합성하였으며, 모두 제품의 매뉴얼에 따라 수행하였다. 시료 채취에서 핵산 추 출까지의 과정은 환경부 국립환경과학원 고시 제 2017-50 호에 의거하여 수행하였다. 선발된 real-time PCR 프라이 머 조합을 사용하여 지하수 시료의 cDNA로부터 HuCoxV- 
$\mathrm{B} 5$ 를 검출하였다. 또한 선발한 프라이머 조합을 일반 $\mathrm{PCR}$ 로 변형 $\left[95^{\circ} \mathrm{C}\right.$ 에서 5 분간 1 회 초기 변성, 35 회 반복 $\left(95^{\circ} \mathrm{C}\right.$ 에서 45 초, $61^{\circ} \mathrm{C}$ 에서 60 초 및 $72^{\circ} \mathrm{C}$ 에서 60 초), $72^{\circ} \mathrm{C}$ 에 서 5 분간 최종 신장]하여 $\mathrm{HuCoxV}-\mathrm{B} 5$ 를 검출하였다. 또한 일반 $\mathrm{PCR}$ 의 검출 민감도가 real-time $\mathrm{PCR}$ 보다 낮은 것 은 감안하여 HuCoxV-B5_F452과 HuCoxV-B5_R604 프라 이머를 이용 1 차 $\mathrm{PCR}$ 증폭 후, 증폭 산물에서 선발 프라 이머를 사용하여 nested PCR을 수행하였다. 환경 시료에 서 PCR 및 nested PCR 시 조성물로 모두 비 특이적 밴드 억제 물질인 $\mathrm{SL}^{\circledR}$ Nonspecific reaction inhibitor (NSRI; LSLK, Korea)를 $3 \mu \mathrm{L}$ 를 포함하여 반응하였다. 한편 nested PCR 증폭 산물들을 MEGAquick-spin ${ }^{\mathrm{TM}}$ Plus Total Fragment DNA Purification Kit (INtRON, Korea)를 사용하여 정제 후 마 크로젠(https://dna.macrogen.com/main.do)에서 염기서열 분 석하였으며, NCBI BLAST (https://blast.ncbi.nlm.nih.gov/
Blast.cgi)로 유사성을 확인하였다.

\section{결과 및 고찰}

총 4개의 후보 프라이머 조합은 모두 HuCoxV-B5 plas$\operatorname{mid}$ 와 cDNA에서 특이적 반응이 나타났으며, plasmid 1 $100 \mathrm{pg} / \mu \mathrm{L}, \mathrm{cDNA} 250 \sim 1,000$ copies의 검출 민감도가 나타났 다. 이 중 후보 프라이머 조합 \#2가 plasmid $1 \mathrm{pg} / \mu \mathrm{L}, \mathrm{cDNA}$ 250 copies로 가장 우수한 검출 민감도를 보였으며, 조합 \#3과 조합 \#4는 조합 \#2에 비해 plasmid 기준 약 10배, $\mathrm{cDNA}$ 기준 약 2 배 수준 낮은 검출 민감도를 보였다. 한 편 조합 \#1은 plasmid 기준 \#3과 \#4와 동등 수준을 보였 으나 $\mathrm{cDNA}$ 에서 상대적으로 낮은 수준의 검출 민감도가 나타났다. 한편, single threshold 자동계산 방식을 기준으로 한 cycle quantification value $(\mathrm{Cq})$ 값은 plasmid $100 \mathrm{pg} / \mu \mathrm{L}$

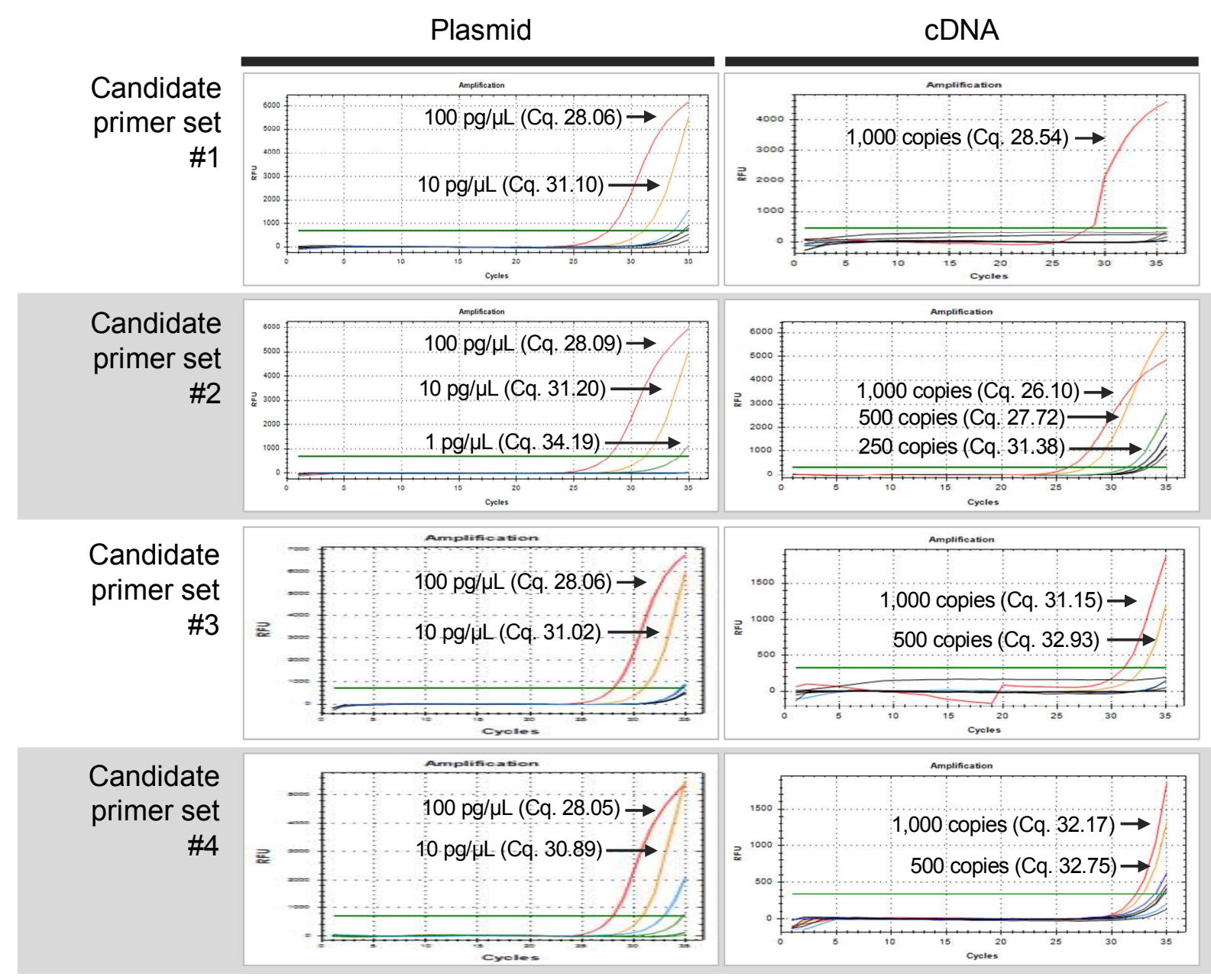

Fig. 2. Specific reaction and sensitivity of four real-time PCR primer sets based on HuCoxV-B5 plasmid and cDNA. 
Candidate primer set \#2

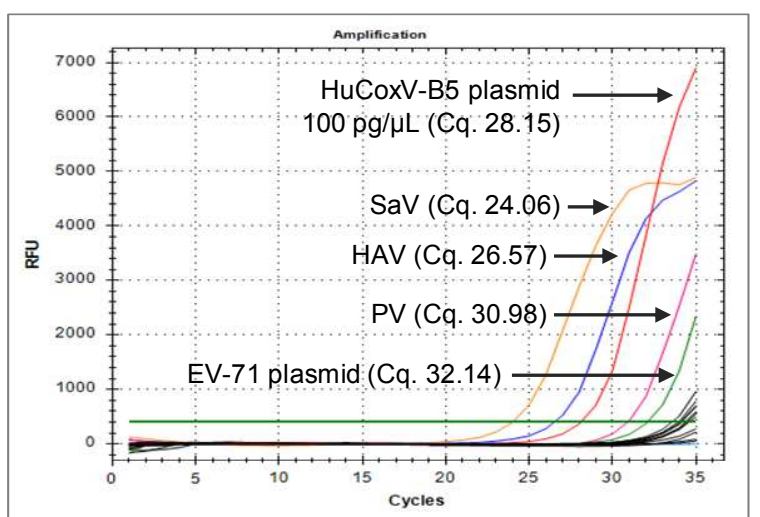

\section{Candidate primer set \#4}

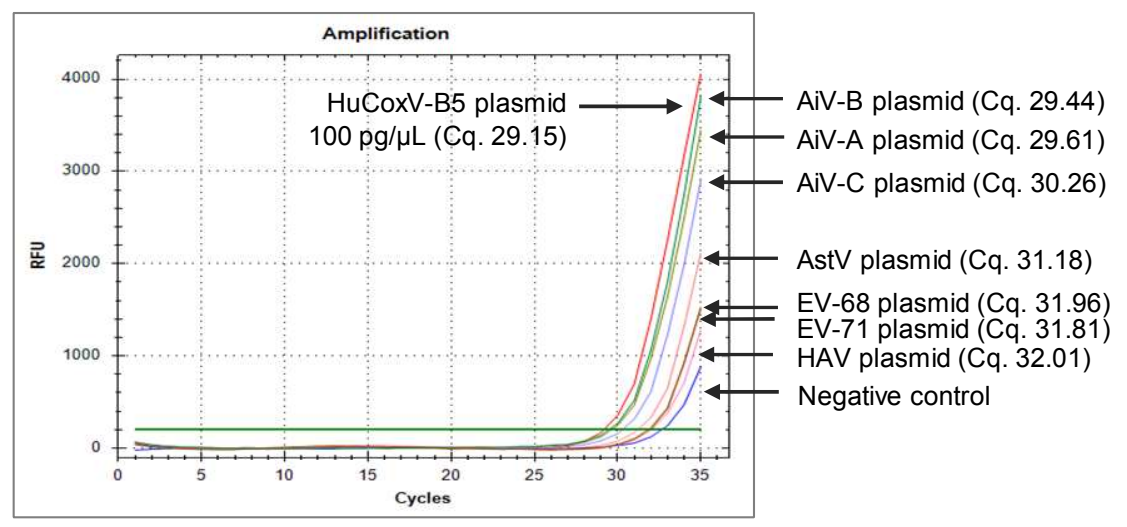

AiV-C plasmid (Cq. 30.26)

AstV plasmid (Cq. 31.18)

EV-71 plasmid (Cq. 31.81)

HAV plasmid (Cq. 32.01)

Negative control
AiV-A plasmid (Cq. 29.61)

Fig. 3. Non-specific reaction of three real-time PCR primer sets based on fifteen reference virus genes.

기준 약 28.05 28.09, $10 \mathrm{pg} / \mu \mathrm{L}$ 기준 약 30.89 31.20 수준 으로 나타났으며 cDNA 1,000 copies 기준 약 26.10 31.17, 500 copies 기준 27.72 32.93 수준으로 나타났다(Fig. 2). $\mathrm{HuCoxV-B5}$ plasmid와 cDNA에서 $\mathrm{Cq}$ 값을 포함한 검출 민 감도 등을 고려하여 조합 \#2, \#3 및 \#4를 선발하였다. 또 한 선발한 3 개의 후보 프라이머 조합들을 대상으로 참고 바이러스 15 종의 핵산에 비 특이적 반응을 분석한 결과, 조합 \#2에서 4종 $(\mathrm{SaV}, \mathrm{HAV}, \mathrm{PV}$ 및 $\mathrm{EV}-71)$ 이 반응하였으며 $\mathrm{Cq}$ 값은 24.06 32.14 수준이었다. 조합 \#4에서는 7종[AiV (A, B 및 C), AstV, EV-71, EV-68 및 HAV]이 반응하였으며, $\mathrm{Cq}$ 값은 29.44 32.01로 나타났다. 반면 조합 \#3에서는 참 고 바이러스 핵산으로부터 비 특이적 반응이 나타나지 않 아 HuCoxV-B5를 특이적으로 증폭할 수 있는 프라이머 조합으로 추정하였으며 최종 선발하였다(Fig. 3).

기존 보고된 HuCoxV-B5 검출용 real-time PCR Ref.\#1과 \#2는 비 특이적 반응이 나타나지 않았으며, cDNA 기준
Candidate primer set \#3

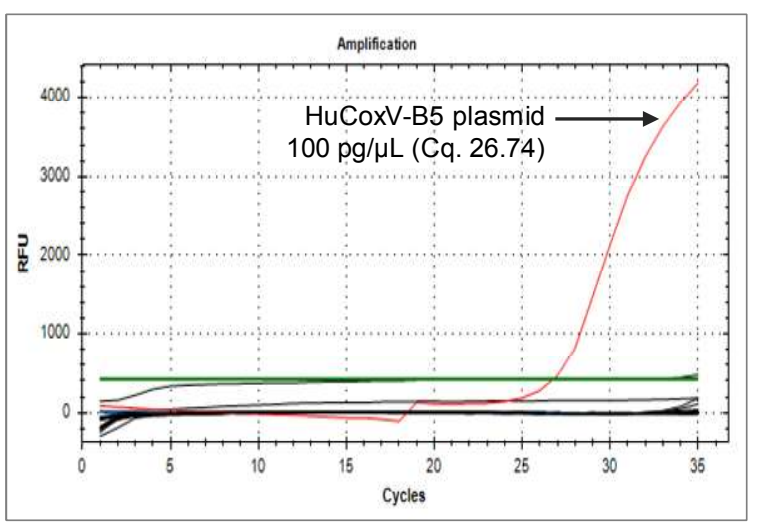
이머가 cDNA 500 copies 주형에서 1,000 relative fluorescence units (RFU) 이상이 분석된 반면 ref.\#1과 \#2는 RFU 값이 약 87.7 105.0 수준으로 낮게 나타나(Data not shown), 선발 프라이머가 포함된 조성물로 반응한 조건에 비해 상대적으로 낮은 검출 민감도가 추정되었다. 또한 선발한 프라이머 조합 \#3으로 수계 환경 시료 10 개에서 추출한 total RNA $(12.3 \sim 74.4 \mathrm{ng} / \mu \mathrm{L})$ 에서 HuCoxV-B5를 검출한 결 과, single threshold $1,000 \mathrm{RFU}$ 를 기준으로 10 개 중 8 개 시 료에서 양성이 추정되었으며, $\mathrm{Cq}$ 값은 약 31.04 33.45 수 준이었다(Fig. 4A). 선발한 프라이머 조합의 일반 PCR 변형 후 지하수 시료에서 HuCoxV-B5를 검출한 결과 모 두 음성으로 나타났다(Fig. 4B). 또한 HuCoxV-B5_F452과 HuCoxV-B5_R604 프라이머를 이용 1차 증폭에서도 시료 10 개 모두 음성, 1 차 증폭 산물과 선발 프라이머 조합을 이용하여 nested PCR을 수행한 결과 1 차 PCR에서 10 개 
(A)

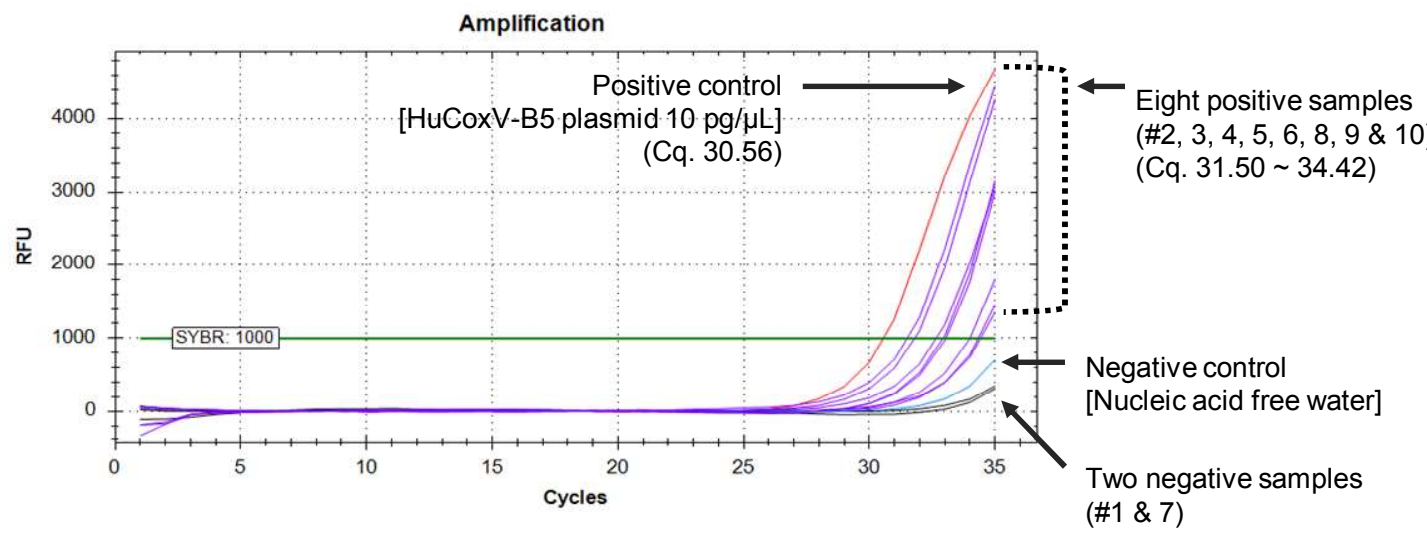

B
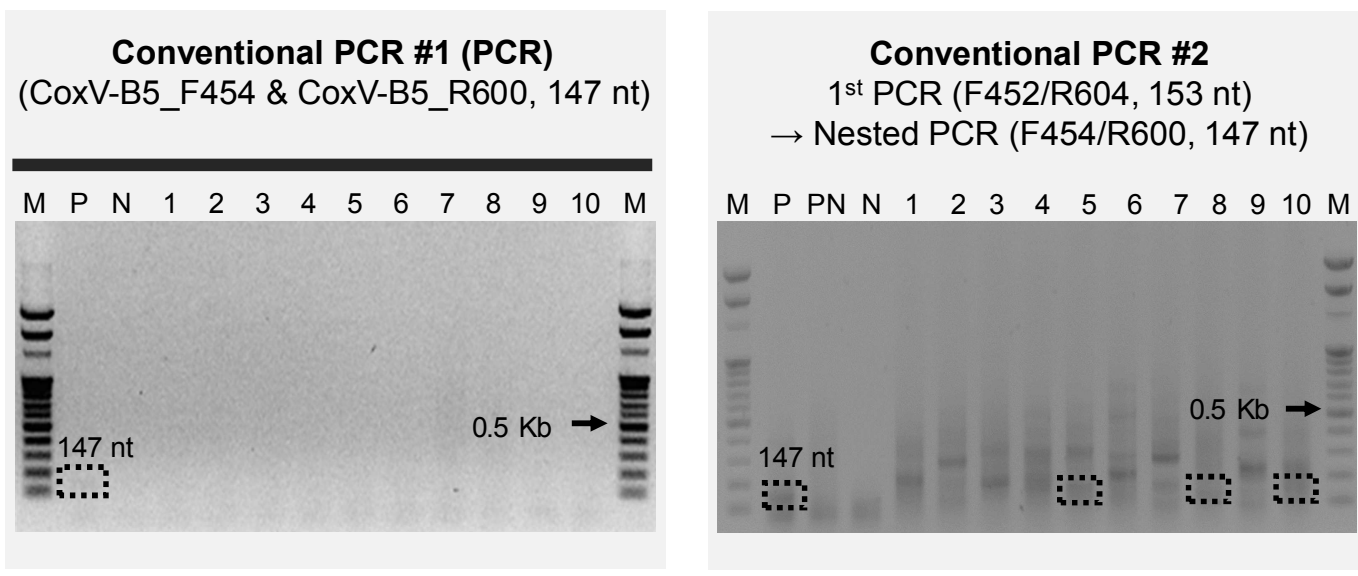

Fig. 4. Evaluation of developed method using the groundwater samples. Panel A. Demonstration test using ten groundwater samples. Panel B. Comparative evaluation of developed method and conventional PCRs. M, 100 bp DNA Ladder maker (Enzynomics, Korea); P, positive control; N, negative control 1 10, sample number.

시료에서 모두 음성이 확인되었고 nested PCR 결과 3개에 서 양성 추정 밴드가 나타났다(Fig. 4B). Nested PCR로 증 폭된 추정 밴드의 염기서열 분석 결과 \#5는 비 특이적 반응, \#8과 \#10은 $\mathrm{HuCoxV-B5}$ 로 최종 분석되어 10개 중 2개에서 HuCoxV-B5 양성으로 나타났다(Data not shown). $\mathrm{PCR}$ 과 nested $\mathrm{PCR}$ 로 반응한 일반 $\mathrm{PCR}$ 에서는 비 특이적 반응을 억제하는 물질을 사용했음에도 불구하고 비 특이 적 증폭이 다수 나타났으며, 이러한 문제점은 일반 nested $\mathrm{PCR}$ 을 이용하여 시료를 검정하는 Lee et al. (2013) 등 다 른 유관 연구들에서 나타나는 결과들과 유사하다. 이러한 문제점을 개선하기 위해서는 비 특이적 반응을 억제하는 물질의 고농도 사용, 물질의 변화 등 $\mathrm{PCR}$ 조성 및 조건 을 설정, 염기서열 분석 전 추정 밴드의 gel-purification 등 일반 PCR 이 후 후속 노력이 필요한 과정을 포함한다.

본 연구에서 개발한 HuCoxV-B5 검출용 프라이머 조합,
조성물 및 조건은 특이적으로 $\mathrm{HuCoxV-B5}$ 를 검출할 수 있을 것으로 보인다. 기존 보고된 real-time PCR 방법 중 약 68분이던 ref.\#1 (Mohamed et al., 2004)의 반응을 약 20 분 단축하였으며, 해당 방법에 비해 상대적으로 우수한 검출 민감도를 보였다. 기존 보고된 real-time PCR 방법 들은 모두 TaqMan probe 기반의 검사법으로 1 개의 프로 브 프라이머를 추가로 사용함으로써 SYBR green 기반의 real-time PCR보다 특이성 향상이 예상되었지만 이번 연구 에서는 확인할 수 없었다. 그러나 프로브 프라이머의 사 용으로 특수 케미컬이 추가되면 SYBR green 기반의 realtime PCR 또는 일반 PCR에서 사용되는 프라이머 조합 대 비 약 25 배의 프라이머 조합 단가 차이가 나는 등 고가 이며, raw material 단가 향상으로 인해 이것은 향후 KIT 개발 시에도 영향을 미칠 것으로 보인다. 또한 선발 프 라이머를 이용한 일반 PCR 방법들(1단계 PCR 및 nested 
$\mathrm{PCR}$ )에 비해 이번 연구에서 개발한 real-time PCR은 1단 계 PCR에 비해서는 약 1시간, nested PCR에 비해서는 약 4시간 수준을 단축할 수 있었으며, 시료 적용 평가에서 상 대적 우수한 결과가 분석되었다. 한편, 지하수 등 수계 환 경 시료는 임상, 식품, 패류 등의 시료에 비해 대량의 매 질 내 미량의 바이러스 오염 및 다수의 PCR 저해 물질이 존재한다(Cho, 2018; Lee and Cho, 2019). 분변-구강 경로로 감염되는 $\mathrm{HuCoxV-B5}$ 의 경우 지하수 중 검출이 가능하다 면 다른 매질로의 활용성이 가능할 것으로 보인다. 이번 연구에서는 10 개 중 8 개의 지하수 시료에서 HuCoxV-B5 양성이 나타났으며 일반 PCR 검사법 대비 특이성, 반응 의 강도 등에서 우수한 결과가 분석되었다(Fig. 4). 따라서 이번 연구에서 개발한 방법은 향후 HuCoxV-B5 관련 증 상이 나타나는 임상 환자에서 신속한 분자진단으로 후속 처방에 기여, 수계 환경, 식품, 패류 등 비 임상에서도 $\mathrm{HuCoxV-B5}$ 모니터링으로 활용되어 공중 보건학적 안전성 등 관련 사고 대응에 기여할 수 있을 것으로 기대된다.

\section{ACKNOWLEDGEMENT}

This work was supported by the Shihan University Research Fund, 2020.

\section{CONFLICT OF INTEREST}

The authors have declared no conflict of interest.

\section{REFERENCES}

Chen J, Zhang R, Ou X, Yao D, Huang Z, Li L, Sun B. Rapid detection of Enterovirus and Coxsackievirus A10 by a TaqMan based duplex one-step real time RT-PCR assay. Mol Cellular Probes. 2017. 33: 8010.

Chen P, Tao Z, Song Y, Liu G, Wang H, Liu Y, Xu A. A Coxsackievirus $\mathrm{B} 5$-associated aseptic meningitis outbreak in Shandong Province, China in 2009. J Med Virol. 2012. 85: 483-489.

Cho KB. Development of Nested PCR Primer Set for the Specific and Highly Sensitive Detection of Human Parvovirus B19. Biomed Sci Lett. 2018. 24: 390-397.

Choi S, Jeong JE, Yun NN, Kim NH, Park YK, Jung EY. Study of the detection of enteric viruses and bacteria in spring-water and groundwater in Busan ('10 '11). J Bacteriol Virol. 2013. 43: 131-139.

Corman VM, Landt O, Kaiser M, Molenkamp R, Meijer A, Chu DK, Bleicker T, Brünink S, Schneider J, Schmidt ML, Mulders
DG, Haagmans BL, van der Veer B, van den Brink S, Wijsman L, Goderski G, Romette JL, Ellis J, Zambon M, Peiris M, Goossens H, Reusken C, Koopmans MP, Drosten C. Detection of 2019 novel coronavirus (2019-nCoV) by real-time RT-PCR. Euro Surveill. 2020. 25: 2000045.

Fontana S, Fiore S, Buttinelli G, Amato C, Veronesi L, Zoni R, Triassi M, Pennino F, Giammanco GM, De Grazia S, Cicala A, Siragusa A, Gamper S, Spertini S, Castiglia P, Cossu A, Germinario C, Larocca AMV, Stefanelli P. Molecular Characterization of Coxsackievirus B5 Isolates from Sewage, Italy 2016-2017. Food Environ Virol. 2019. 11: 440-445

Gullberg M, Tolf C, Jonsson N, Mulders MN, SK C, Hovi T, Lindberg AM. Characterization of a putative ancestor of Coxsackievirus B5. J Virol. 2010. 84: 9695-9708.

Hardinge P, Murray J. Reduced false positives and improved reporting of loop-mediated isothermal amplification using quenched fluorescent primers. Sci Rep. 2019. 9: 3-13.

Hu YF, Yang F, Du J, Zhang T, Xue Y, Jin Q. Coxsackievirus B5, associated with neurological hand, foot and mouth disease, China. J Infection. 2012. 65: 189-191.

Hyeon JY, Hwang S, Kim H, Song J, Ahn J, Kang B, Kim K, Choi W, Chung JK, Kim CH, Cho K, Jee Y, Kim J, Kim K, Kim SH, Kim MJ, Cheon DS. Accuracy of diagnostic methods and surveillance sensitivity for human enterovirus, South Korea, 1999-2011. Emerg Infect Dis. 2013. 19: 1268-1275.

Jaianand K, Saravanan N, Gunasekaran P, Sheriff A. Development of a new method for diagnosis of Group B Coxsackie genome by reverse transcription loop-mediated isothermal amplification. Indian J Med Microbiol. 2011. 29: 110-117.

Kang LH, Oh S, Park JW, Won YJ, Ryu S, Paik SY. Simultaneous detection of waterborne viruses by multiplex real-time PCR. J Microbiol. 2013. 51: 671-675.

Kopecka H, Brown B, Pallansch M. Genotypic variation in Coxsackievirus B5 isolates from three different outbreaks in the United States. Virus Res. 1995. 38: 125-136.

Lee HK, Jeong YS. Comparison of total culturable virus assay and multiplex integrated cell culture-PCR for reliability of waterborne virus detection. Appl Environ Microbiol. 2004. 70: 3632 -3636 .

Lee S, Cho KB. Development of Reverse Transcription Semi-nested PCR Primer Pairs for the Specific and Highly Sensitive Detection of Human Aichivirus A1. Biomed Sci Lett. 2019. 25: 331 -338 .

Lee S, Jang J, Bae K, Lee W, Chung H, Park S. Prevalence of human Norovirus by genotype in contaminated groundwater 
in Korea over the last decade (2007 2016). J Microbiol. 2018. 56: 926-931.

Lee S, Kang EH, Chu YM, Shin YG, Ahn TY. Development of PCR diagnosis system for plant quarantine seed-borne Wheat streak mosaic virus. Korean J Microbiol. 2013. 49: 112-117.

Lee S, Kim JH, Choi JY, Jang WC. Loop-mediated isothermal amplification assay to rapidly detect Wheat streak mosaic virus in quarantined plants. Plant Pathol J. 2015. 31: 438-440.

Lee S, Lee JY, Kim H, Kim JH, Rho JY. Development and Optimization of a Reverse Transcription Hemi-Nested PCR Primer for the Detection of Potato Mop-Top Virus at Quarantine Inspection Sites in Korea. Indian J Microbiol. 2017. 57: 253-256.

Mohamed N, Elfaitouri A, Fohlman J, Friman G, Blomberg J. A sensitive and quantitative single-tube real-time reverse transcriptase-PCR for detection of enteroviral RNA. J Clin Virol. 2004. 30: 150-156.

Oberste MS, Maher K, Kilpatrick DR, Pallansch MA. Molecular evolution of the human enteroviruses: correlation of serotype with VP1 sequence and application to Picornavirus classification. J Virol. 1999. 73: 1941-1948.

Papa A, Dumaidi K, Franzidou F, Antoniadis A. Genetic variation of Coxsackievirus B5 strains associated with aseptic meningitis in Greece. Clin Microbiol Infection. 2006. 12: 688-691.

Rezig D, Yahia AB, Abdallah HB, Bahri O, Triki H. Molecular characterization of Coxsackievirus B5 isolates. J Med Virol. 2004. 72: 268-274.

Schneider L, Blakely H, Tripathi A. Mathematical model to reduce loop mediated isothermal amplification (LAMP) false-positive diagnosis. Electrophoresis. 2019. 40: 1-12.
Tan EL, Yong LLG, Quak SH, Yeo WCA, Chow VTK, Poh CL. Rapid detection of Enterovirus 71 by real-time TaqMan RTPCR. J Clin Virol. 2008. 42: 203-206.

Triantafyllopoulou A, Tapinos N, Moutsopoulos HM. Evidence for Coxsackievirus infection in primary Sjögren's syndrome. Arthritis \& Rheumatism. 2004. 50: 2897-2902.

Yoo JE, Lee C, Park S, Ko G. Evaluation of Various Real-Time Reverse Transcription Quantitative PCR Assays for Norovirus Detection. J Microbiol Biotechnol. 2017. 27: 816-824.

Wagenknecht LE, Roseman JM, Herman WH. Increased incidence of insulin-dependent diabetes mellitus following an epidemic of Coxsackievirus B5. American J Epidemiol. 1991. 133: 1024 -1031 .

Zhang G, Wilsden G, Knowles NJ, McCauley JW. Complete nucleotide sequence of a Coxsackie B5 virus and its relationship to Swine vesicular disease virus. J Gen Virol. 1993. 74: 845-853.

Zhao G, Yin G, Zhao H, Li G, Meng B, Hu X, Li Y, Wang Y, Zhao $\mathrm{H}$. Two reverse-transcription-loop-mediated isothermal amplification systems for highly sensitive detection of Enterovirus 71 and Coxsackievirus A16. Academic J. 2013. 7: 4443-4450.

https://doi.org/10.15616/BSL.2020.26.4.302

Cite this article as: Cho KB. Development and Evaluation of a SYBR Green-Based, Real-time Polymerase Chain Reaction for Rapid and Specific Detection of Human Coxsackievirus B5. Biomedical Science Letters. 2020. 26: 302-309. 